\title{
Enhancing Math Learning Using Synchronous Online Teaching
}

\author{
Anu Divakaran*
}

\section{Abstract}

In today's world, digital technology enables us to access knowledge from anywhere, anytime and learn at our pace. This online learning process when made interactive and collaborative can lead to effective learning. Synchronous online learning satisfies these requirements of online and distant learning with focus on the quality of instruction and how effectively learners are engaged. As the name implies, synchronous learning allows instruction and learning to happen in real-time, but not necessarily in the same place. It provides all the advantages of digital, online and distant learning with an added benefit of bringing human interaction to the learning environment which is not available in an asynchronous learning platform. This paper focuses on using synchronous learning environment to enhance mathematics learning. While an abundant source of materials are available online related to mathematics, support from the teacher is always an added advantage especially since mathematics includes problem-solving and logical reasoning. The students will remain engaged and motivated in a synchronous learning environment than in an asynchronous one since immediate feedback is highly appreciated by the students when faced with a critical and challenging concept. If both the teacher and

* School of Education, Christ University, Hosur Road, Bengaluru, India; anu.divakaran@ed.christuniversity.in 
the students are familiar with the use of the synchronous technology tools, synchronous learning can combine the benefits of both face-to-face and online digital learning while bringing the learners together through collaborative learning. Collaboration brings in new ideas and methods of learning. Hence it is inevitable that the present educators make use of this opportunity to humanize online and distant learning by familiarizing themselves with efficient tools and making use of the discoveries and inventions in the field of education, computer science, anthropology, and psychology. There are many tools and software packages available for implementing synchronous learning, and the choice depends on the type of interactions and the pedagogy preferred by the teacher.

Keywords: Synchronous learning, Mathematics Learning, Online Learning, Digital learning, real-time learning

\section{Introduction}

Mathematics is often considered as an abstract subject and students often fail to connect what they learn with the world. Most of the times, the subject is taught in a rote method in a traditional classroom and majority of the students dread about failure in the subject. Teachers also lack support and confidence in the teaching of Mathematics. The key to a successful teaching and learning of Mathematics is to make the students understand that Mathematics is more than just formulas and step by step procedures (NCERT, 2005).Digital resources available in the internet to visualize and model the mathematical concepts can help students in effective learning. Even while all information is available online, the significance of the guidance and support provided by a more knowledgeable person is unquestionable. While an asynchronous online learning environment provides a constructivist learning through collaboration (Lan \& Ah-Teck, 2014), a synchronous learning environment adds human interactions in real-time and live conversations to it which is essential to Mathematics where it is required to solve problems and demonstrate how the results are achieved(Finkelstein, 2006). Some examples of synchronous learning tools are WebEx, Elluminate, Adobe Connect, Blackboard Collaborate, etc. 


\section{Need}

When many options are available for online mathematics learning in the form of various resources and tools, synchronous learning should be usedonly when it is uniquely appropriate. The purpose of using synchronous tools should be evident and deliberate based on what is going to be achieved exclusively when the learners and instructor meet online. Compared to asynchronous online learning, the following functions are served by synchronous learning which are essential for effective mathematics learning (Finkelstein, 2006).

- Practical Instructions from experts in a planned and constructivist manner irrespective of the geographic location of the facilitator or the learner.

- Collaborative activities with peers instantaneously, also reducing the time spent on the task.

- Support and scaffolding from the right person at the moment when most needed or faster.

- Informal exchange of ideas and Socialization through instantaneous online text or voice chats.

- To achieve learning objectives in mathematics that cannot be achieved using asynchronous learning tools.

- Extended help from experts or knowledge communities

According to a report published in 2011 by Hanover Research, India is one among the countries adopting distance learning at the fastest rate with approximately $24 \%$ of higher education students enrolled in distance education through national and state open universities and other public institutions (Hanover Research, 2011). There is also a vast potential in the country for distance learning as the traditional universities and colleges cannot accommodate all the higher education aspirants, according to Commonwealth of Learning report in 2007.

\section{Literature Review}

A study(Park \& Bonk, 2007) was conducted on synchronous technology integration into a distance graduate education program at a large state university. The students used Breeze, a synchronous 
conferencing tool, (renamed Adobe Connect Professional) for various meetings and activities as part of their course, facilitated by the faculty during 49 sessions. The study found out that $85 \%$ of the students benefitted by the timely feedback, dynamic, and effective interactions, and required support by the instructors. But at the same time, time limits, insufficient reflection time, tool-related problems, and peers' inadequate preparation in using the tools and technology were recognized as the primary challenges. The study also mentions about the benefits of exchanging multiple perspectives, strengthening social presence and providing of emotional supports and verbal cues in a synchronous learning platform. The strategic instructional supports and the right usage of communication tools were some of the critical skills and knowledge of the instructors in online pedagogy, and these were influential in the positive learning experience of the students. Some instructional strategies employed were to prepare the students in advance by giving guidelines and rules, practice sessions and materials for critical thinking. The active involvement of the students was promoted through ensuring small student group, proper structuring, scaffolding and reflective papers.

Another study (Bower, 2011) analyzed the collaborative and technological competencies of the teachers and students in effectively achieving the learning outcomes using synchronous web-conferencing tools using a design-based research process. The pedagogies used for the study were refined and iterated to arrive at the findings. The analysis established that a range of competencies for synchronous collaboration like operational competence, interactional competence, managerial competence, and design competence are required which otherwise can lead to misunderstandings and misuse. These skills were observed to be hierarchical in nature and were found to be influenced by the type of pedagogy applied. The instructor needed low-level managerial competence in a teacher-centred pedagogy and students required operational competencies. While student-centred pedagogies required higher-level management for both the instructor and students,apart from thehigher design skills expected from thecourse designers. The study also found that the students could also design the learning environment after they had developed confidence in using the web-conferencing system. 
Researcher (Lan \& Ah-Teck, 2014)have highlighted various factors to be considered while designing an online learning environment, requirement of interaction between students and teachers and with peers being one such factor especially for a subject like Mathematics. The article emphasized that the key to sustain effective learning in a virtual environment was high motivation in learners, for which synchronous interactions were very effective. The review study recommended inclusion of realistic math activities originating from real-life situations and which encouraged collaboration with others and teachers in real-time. The paper recommended the synchronous learning environment to have a minimum number of interactions to improve the effectiveness of math learning.

Researchers (Li, Amin, \& Uvah, 2011)have also discussed about a web-conferencing software package for distance mathematics course offered for a master's program called "Elluminate Live." The study conducted on this synchronous learning platform included both distance and face-to-face students and was followed by another e-learning platform, D2L for active and effective interactions. The statistical analysis of data showed that there was no significant difference between the learning of face-to-face students and the distant students and the student enrolment ratio for the course improved drastically in successive years. To improve the quality of instruction, surveys were conducted and the students were also assessed periodically, followed by a periodical streamlining of the methodology based on the outcome of the assessments. The study also cautioned that such synchronous online learning could be less effective in much younger and less committed students.

Martin, Parker, \& Deale(2012)examined interactivity in synchronous virtual classrooms using a multiple case study design and generalizations were arrived at through cross-case analysis. By eliminating or limiting the problems due to unfamiliar interface, the learners could successfully interact with the facilitators, peers, and content. The teaching style of the instructor and conveying of expectations from the learners and following it up had direct influence on the learner-instructor interactions and the students could ask or express without interrupting others through text chat 
with the instructor. The interactions could be better organized using hand-raising and polling tools. The peer interactions were enhanced using options of private and group communication which increased collaboration and motivated the learners. The study also emphasizes that the teachers who used synchronous systems to impart can straightaway address student understanding of the instructional ideas in an online setting.

\section{Synchronous learning}

Synchronous learning is instructor-led where students learn from teachers or peers in real time, but not in person can be in the form of interactive webinars, educational video conferences, online discussions, and lectures that are broadcast live. The learning can occur individually or in groups geographically located at different places, at the same time. The work and the sharing are seen on an electronic "whiteboard" in most platforms, with audio and video conferencing also being present. A typical synchronous learning platform consists of most of the following features:

- Audio and Video conferencing

- Application sharing

- Interactive whiteboards

- Synchronized web browsing

- Group text chat

- Control for the instructor

- Electronic hand-raising and feedback

- Facility to view student screens

- Breakout groups for collaborative activities

- Third-party multimedia learning resources

- Voice over IP (VoIP)

- Facility to record and store classes

\section{Pedagogy of using Synchronous Learning for Mathematics}

An important approach while teaching mathematics on a synchronous learning platform is to prioritize on the engagement and interaction of the learners rather than on the design of the content even though it is necessary. Thus a real-time online 
learning is student-centred rather than teacher-centred. The facilitator or the teacher should clearly convey the expectations from the learners in advance and should plan the transactions adequately. The learners should be encouraged to have clear and concise dialogue. Mathematics learning online heavily depends on the use of web-based resources to understand and visualise the abstract and symbolic concepts. The facilitator should be aware of the ability of the students in using the technology tools and should balance its emphasis and usage. They should also take care of the quality of discussions and give prompt feedback. The sense of community and guidelines for participation and engagement should be established (Palloff \& Pratt, 2007). The skill level, motivation, and attitude of the students affect the learning in a synchronous environment. The facilitator can take advantage of interactive learning, sense of community, better accountability and retention of the students that are available with a synchronous learning environment. It is possible to give real-life problems to students which they can visualize and analyze using the software packages and arrive at the solutions which would be difficult to enact in a traditional classroom setting. The method of assessing the students in a synchronous environment is difficult and rubrics for evaluation should be creative to be effective (Mayes, Luebeck, Mays, \& Niemiec, 2006).

\section{Advantages of Synchronous learning}

Some of the unique advantages of synchronous learning in education are:

- Helps the students to connect with not only their own teachers and peers but also with recognized experts in the field regardless of the geographical distance and difference in time zones.

- Provides opportunities to both the teachers and the students to expand their knowledge outside the classrooms.

- Helps students who are homebound or limited mobility to connect with their classrooms and participate in learning.

- Helps the faculty to conduct classes when they are not able to come to classes due to an emergency. 
- Supports real-time collaboration, interaction, and immediate feedback

- Encourage students to learn together and in turn, develop cultural understanding

- Personalisedlearning experience for the students

- Real-time discussion opportunities for students promoting student engagement

- Collaboration, in turn, can help the students to expand their knowledge and improve retention.

- Active interaction can lead to an associated community of like-minded students

- Saves travel expenses and time

- The real-time capabilities and analytical thinking of the students can be assessed.

\section{Conclusion}

The paper highlights how synchronous learning can enhance mathematics learning. It can be seen that synchronous learning can be effective in a distant online education when used for an appropriate math concept. The pedagogy for this requires that the facilitator to be creative, flexible and more essentially adaptive. Even though the potential using synchronous tools are huge, it also offers a lot of challenges to fit the tool within the curriculum sensibly. In India, the access to technology tools and costs of implementing synchronous learning platforms are a challenge. The disparities in the hardware and software tools used by the learners and teachers should be eliminated which can be complex in Indian context. They may also require a training session, in the beginning, to familiarize with the tools. The instructors can undergo training through online training courses, thus experiencing the learning first-hand as learners themselves. Synchronous learning has a huge scope in enhancing math learning when factors like teacher presence, social presence, and cognitive presence are incorporated (Morrison, 2014). 


\section{References}

Bower, M. (2011). Synchronous collaboration competencies in webconferencing environments - their impact on the learning process. Distance Education, 32(1), 63-83.

Finkelstein, J. E. (2006). Learning, Live Online. In Learning in Real Time: Synchronous Teaching and Learning Online (pp. 1-11). San Francisco: Jossey-Bass.

Hanover Research. (2011). Trends in Global Distance Learning. Washington DC: Hanover Research.

Lan, D. H., \& Ah-Teck, J. C. (2014). Intermediate Math through an Online Learning Environment. The Quest for Improved Student Achievement and Well-Being: A Journal of Educational Inquiry and Practice, 8.

Li, K., Amin, R., \& Uvah, J. (2011). On Synchronous Distance Teaching in a Mathematics MS (Master of Science) Program.US-China Education Review, 761-767.

Martin, F., Parker, M. A., \& Deale, D. F. (2012). Examining Interactivity in Synchronous Virtual Classrooms. The International Review of Research in Open and Distance Learning, 13(3), 227-260.

Mayes, R., Luebeck, J., Mays, M., \& Niemiec, E. (2006). Mathematics On-line: A Virtual Reality or Impossibility. Retrieved from The Institute for Mathematics Learning (IML) West Virginia University: http://www.iml.sitespace.wvu.edu/ r/ download/15292

Morrison, D. (2014, March 9). The Next-Big-Thing in Online Education...Learning in Real Time. Retrieved from Online Learning Insights: https://onlinelearninginsights. wordpress.com/tag/synchronous-tools-for-onlinelearning/

NCERT. (2005). National Curriculum Framework 2005. Retrieved from National Council Of Educational Research And Training: www.ncert.nic.in/ rightside/links/ pdf/ framework/english/nf2005.pdf 
Palloff, R. M., \& Pratt, K. (2007). Building Virtual Communities: Techniques That Work! 23rd Annual Conference on Distance Teaching $\mathcal{E}$ Learning.Board of Regents of the University of Wisconsin System.

Park, Y. J., \& Bonk, C. J. (2007). Is Online Life a Breeze? A Case Study for Promoting Synchronous Learning. MERLOT Journal of Online Learning and Teaching, 3(3). Retrieved from http:// jolt.merlot.org/ vol3no3/park.htm Synchronous conferencing - Wikipedia, the free encyclopedia. (n.d.). Retrieved from https:// en.wikipedia.org/ wiki/ Synchronous_conferencing 